\title{
Reflections on Foreign Linguistics Research
}

\author{
Zhao Huiyan ${ }^{1, a}$ \\ ${ }^{1}$ Anshan Normal University, Anshan,Liaoning P.R.China 114007 \\ a10013532@qq.com
}

Keywords: Reflections, Foreign Linguistics, Research

\begin{abstract}
This paper contemplates the three questions of foreign linguistics: (1) the ultimate goal of foreign linguistics research. From the reanalysis of the phenomenon of "two skins", the author thinks that the ultimate goal of foreign linguistics research should serve the language construction of China; (2) the innovation of foreign language research. From the analysis of what is not innovation to start, put forward foreign language research innovation must have local awareness, problem awareness and theoretical awareness; (3) foreign language research to the top of the earth, It is pointed out that foreign language research should aim at the forefront of academic research at home and abroad, pay attention to theoretical innovation and pay attention to the problems that need to be solved in front of them, especially foreign language teaching and translation. The article also emphasizes the importance of laying the basic skills of language, especially to improve the level of mother tongue in foreign language research.
\end{abstract}

\section{Introduction}

In recent years, in the context of foreign language research, Chinese language research has also developed by leaps and bounds. Linguistics mainly includes Chinese linguistics and foreign linguistics and the major institutions are based on this set up professional. In the process of developing linguistics in China, engaged in Chinese scholars and scholars engaged in English research independent of each other, there is no intersection between each other and this is the academic circle of the famous two strange phenomenon. This phenomenon not only did not bring benefits to our language education, but has become a serious obstacle to our language education factors for this phenomenon should be changed.

\section{The Ultimate Goal of Foreign Linguistics Research}

\subsection{Research on the "Two Skin" Problem.}

Chinese linguistics can be divided into Chinese linguistics and foreign linguistics two blocks, even the subjects have "linguistics and applied linguistics" and "foreign linguistics and applied linguistics" of the points, although the academic community does not agree, But it is an indisputable fact. Engage in foreign language and engage in Chinese mutual exchanges, in their respective academic conferences is difficult to see the other side of the figure. This is a very unique phenomenon in the world. In the early 1980s, Lv Shuxiang et al. (1987) had spoken loudly to eliminate the phenomenon of "two skins". There were also two symposiums held at the beginning of this century, but the situation seemed to be fundamentally unchanged. What is the reason for this? Originally we thought it was because the Chinese people engaged in Chinese language foreign language difference, engage in foreign language Chinese poor. However, the foreign language level of Chinese college students has improved greatly in the past two decades. Many people have also traveled abroad and have come into contact with foreign linguistics, but the situation of "two skins" remains. It can be seen that the foreign language difference is not the root cause of the "two skins". So, where is the root cause? It seems that we need to examine from a deeper level. This is the beginning of the phenomenon from the unique.

As mentioned above, "two skins" is a unique phenomenon in Chinese language research institute, 
almost impossible to see in other countries. It is hard to imagine that, for example, in the United Kingdom, the United States or France, Russia, English linguistics, French linguistics or Russian language learning and general linguistics research "two skin" phenomenon. From the "uniqueness", I think the reason for the "two skins" is at least two, one is from the Chinese side, the Chinese language and its text in the world language is too special, and their own need to study too much As well as many people immersed in it for life, but also only a small part of them or even just a corner, such as philology, exegesis or grammar what, once into it is difficult to jump out, no matter how good the outside It is difficult to use; the other is from the foreign language side, foreign language theory is endless, with each passing day, it is almost overwhelmed, a researcher spent a number of years of energy, can get through one or two is not easy, not to mention foreign theory Still refurbished, a little careless and behind, and had to desperately learn again. And these theories are all formed on the basis of Western language, because of the great differences between Western languages and Chinese, do not know how to use Chinese, the results had to stay in foreign linguistics on foreign linguistics, foreign theory to explain foreign Linguistic. At least just occasionally a few examples of Chinese prove the universality of foreign theory. And fundamentally speaking is always free from the outside of Chinese linguistics. Some people further believe that learning foreign linguistics as long as the problem can explain foreign language, even the Chinese examples do not have to give. It is more consciously adhere to the "two skin" position. Thus, if these two problems are not resolved, the "two skins" phenomenon cannot be fundamentally eliminated. And to solve these two problems, it is not just learn foreign language, learn Chinese so shallow problem, but a deeper theoretical problem. Because in the final analysis, these two questions is actually a problem, that is, must find a Chinese linguistics and foreign linguistics between the good interface. In this way, from the perspective of Chinese linguistics, there will be a need to recognize that the Chinese language is special, as a member of the world language family, it always has in common with the world language, to really attack Chinese linguistics from the foreign language theory, we must find a foothold to understand the basic goal of foreign linguistics research is to solve the problem of Chinese language.

\subsection{Foreign Linguistics Research Must Eventually Serve the Language Construction of China.}

It said that the ultimate goal of foreign linguistics research must serve the language construction of China, many people probably disagree, that this is just the task of Chinese people engaged in research, engage in foreign language Well, had to learn a foreign language on the line: foreign language theory can guide our Chinese do not care, as long as we can help us learn a foreign language on the line. We cannot agree with this. However, if foreign language teaching, foreign language research as a cause, we must think about these issues: First, we are really in the school, we are really in the school, foreign language, but do we learn foreign languages in the vacuum? Do we learn foreign languages on the basis of forgetting their mother tongue? As a Chinese, we learn foreign languages (eg English) and learn their mother tongue with Anglo-American people and those who speak other languages to learn English, is it exactly the same? What are the same or different laws inside? Will lead to the same or different methods? Do not need to study or not worth studying?

Second, in foreign language teaching in China, in the final analysis is the Chinese foreign language teaching. Foreign language theory has produced foreign language teaching methods, such as traditional linguistics has produced a grammar translation method, structuralism has produced a sentence replacement method and functionalism produced a situational law, these methods in foreign environments, produced a size ranging from the effect, but also exposed the size of the inadequacies. But whether these theories and methods can be used in the context of China, the environment of Chinese, foreigners will not tell us the ready answers, through our own research and practice. Foreign language theory and language teaching theory if not combined with the reality of Chinese learning foreign language, can be said to be useless; and to combine this reality, do not understand Chinese, do not study Chinese and do not understand the Chinese language learning and 
foreign language learning, that cannot be imagined.

Third, the study of foreign linguistics is in the end for what? Some people say that is to study foreign linguistics itself; some people say that is in line with the international linguistics research; some people say that in order to study the universal language, But enough. But from these answers I cannot see the exclusion of Chinese truth. I would like to ask: the same study of foreign linguistics, where the strengths and weaknesses of the Chinese people? Not by you know foreigners do not understand or do not understand the Chinese? If you do not put your eyes in the eyes of this specialty to foreign people do not have the facts and laws of Chinese? If you really think that the language of the whole language cannot be included in the Chinese language theory? The foreign linguistics we study is an ordinary linguistics that is universally applicable to all languages of mankind, and it is even more necessary for Chinese to participate, and this task falls more in foreign language linguistics (if it is understood as an ordinary language Learn the words of the researcher. Therefore, the study of Chinese can even be said to be a natural mission of foreign linguistics researchers. Finally, fourthly, Chinese language researchers have a very good tradition, from Ma Jianzhong to Zhao Yuanren, from Wang Li to Lv Shuxiang, who study and study foreign linguistics, whose ultimate goal is to establish and develop Chinese own language learn. This fine tradition should not end to our generation. Especially in the current situation, after a hundred years of humiliation, China is re-emerging, Chinese linguistics has to re-rise, as Chinese linguists, whether it is engaged in Chinese linguistics, or engage in foreign linguistics, Should be in this great cause to assume their own historical responsibility.

\section{The Goal of Foreign Linguistics Research}

In Chinese subject system, the linguistics is divided into two parts, namely, Chinese linguistics and foreign linguistics, this division has been a lot of scholars questioned, especially foreign scholars, in their view, the language disciplines if the study is limited to foreign languages, then the study of Chinese language is very unfavorable. This idea of foreign scholars is correct, the main purpose of the division is to further study linguistics and division is not the same as the separation. In essence, linguistics does not have Chinese linguistics and foreign linguistics, and linguistic studies should not be limited to the classification of Chinese and foreign languages.

The ultimate goal of studying foreign linguistics is to better serve and develop Chinese language. The reason is that people in the study of foreign languages, it is impossible to completely ignore their mother tongue. For the Chinese people, in the process of learning a foreign language and the British and American countries will not learn their mother tongue. We need to understand the similarities and differences between Chinese and foreign languages in the course of the study, and the same methods and different methods of the two languages. In such studies and contrasts, we can quickly find time and effective learning methods. If the theory of foreign language and language teaching is not combined with the reality of Chinese learning, it does not have any usefulness. If you do not understand the difference between Chinese language learning and foreign language learning, we cannot use foreign language to study. Therefore, research scholars in the study of foreign linguistics must be on the Chinese language to be studied.

\section{The Foreign Language Research Needs to be Innovative}

In the process of studying foreign languages, the state cannot only be confined to the traditional research mode, but this research mode can only hinder the process of research and will not play a role in the study of foreign languages. Researchers in the foreign language research and innovation can be from the following two aspects:

\subsection{Integrate Local Ideas into the Research Process.}

Researchers in the study of foreign languages remember that foreign language is in the social environment and social background generated. It is originated in foreign countries, so foreign studies of the language is the most realistic situation, in addition, the study of foreign languages 
should always be based on the long-term accumulation of the culture on the basis of the foundation. Therefore, foreign research scholars in the study of foreign language, his research level than the Chinese scholars to be more professional, and Chinese language research scholars in the study of foreign languages, there is still a big gap. In order to achieve breakthrough and innovative achievements in the research process, the research scholars need to integrate Chinese into Chinese, and combine Chinese and foreign languages to carry out comparative studies, which will achieve a multiplier effect. On the surface, the researchers do not deal with the Chinese language in the study of foreign languages, but in practice, they are thinking about the service of Chinese language construction in the course of the study.

\subsection{Always Keep the Problem Conscious.}

The problem is an era of development and progress of the voice, all the reform and development need to continue to solve the problem and answer the question, from this point it can be seen that the establishment of the problem consciousness is quite necessary. In the study of foreign language process, the concept of the problem is mainly reflected in the following two aspects: First, in the study of language process to the Chinese language and China actually into it; second, to correctly understand the true meaning of integration. These two aspects require scholars to study foreign languages in the full understanding of the Chinese language under the premise of the use of foreign language analysis and draw the corresponding conclusions, but also to consider whether the conclusions of the study in line with the characteristics of Chinese language, let the two achieve the perfect combination, rather than tough together.

\section{Conclusion}

There is always a phenomenon of "two skins" in language research in China, which is not only influenced by the particularity of Chinese language, but also influenced by foreign language. Therefore, research scholars in the study of foreign languages, we should pay attention to the practical purpose of learning the language, and in the research innovation, so that the Chinese language and foreign language to achieve a perfect combination, and ultimately to further develop language research.

\section{References}

[1] Wang Pei. On foreign linguistics research and exploration [J]. Test Weekly. 2017 (70)

[2] Li Qian. On the study of foreign linguistics and exploration [J]. Journal of Jiamusi Vocational College. 2016 (03)

[3] Conference Secretary Group. Jiangsu Province Foreign Language Society of the first annual meeting and the fifth academic forum held [J]. Jiangsu foreign language teaching and research. $2013(02)$

[4] The second Jiangsu province foreign language academic forum summary report [J]. Jiangsu foreign language teaching research. 2010 (02)

[5] The first Jiangsu foreign language academic forum will be held in Nanjing [J]. Language Science. 2009 (02) 